\title{
Right Pediatric Site Selection and Technology
}

\author{
Tricia Kleidon and Amanda Ullman
}

\begin{abstract}
Venous access is one of the most basic yet critical components of patient care in both inpatient and ambulatory healthcare settings. Safe and reliable venous access is vital to patients and their families to ensure timely and complication-free treatment. Obtaining reliable access in the pediatric patient can be challenging due to various factors including physical (small, mobile veins, excessive subcutaneous tissue) and emotional (pediatric patients are often less cooperative, especially in the awake patient). The use of ultrasound to insert both peripheral and central venous access devices has improved success rates of insertions and reduced complications associated with insertions.
\end{abstract}

A variety of vascular access options exist, and selection of the most appropriate site helps to ensure vessel health and preservation and should be tailored to each indi-

T. Kleidon $(\bowtie)$

Alliance for Vascular Access Teaching and Research (AVATAR), Queensland Children's Hospital,

Brisbane, QLD, Australia

e-mail: tricia.kleidon@ health.qld.gov.au

A. Ullman

Alliance for Vascular Access Teaching and Research (AVATAR) Group, Menzies Health Institute Queensland, School of Nursing and Midwifery, Griffith University, Brisbane, QLD, Australia e-mail: a.ullman@griffith.edu.au vidual patient need. Prior to selecting the insertion site, clinicians should consider the patient's condition, developmental age (discussed further in Chap. 13), skin condition, previous vascular access history, duration of infusion therapy, and patient preference where possible.

\section{Keywords}

Pediatric site selection - Pediatric technologies $\cdot$ Pediatric considerations for VAD placement

\subsection{Site Selection for Peripheral Devices}

\subsubsection{Peripheral Intravenous Cannula (PIVC)}

\subsubsection{Vein Options}

A detailed understanding of the venous systems of the upper and lower extremities facilitates successful cannulation. The upper extremities have two primary venous systems: the cephalic and basilic veins (Fig. 15.1).

When choosing the best vein for each individual patient, consider the length of treatment (e.g., one-off infusion versus IV therapy for multiple 
Fig. 15.1 Veins of the upper arm (used with permission N. Moureau PICC Excellence)

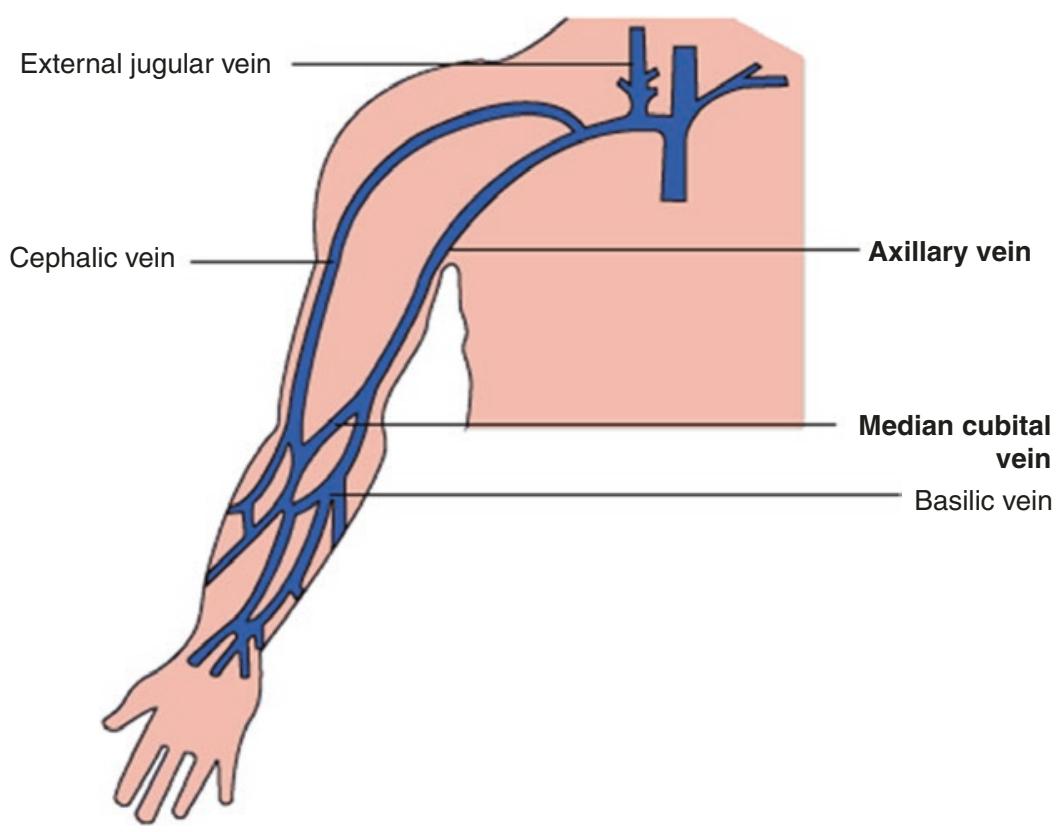

days), type of treatment to be infused (such as $\mathrm{pH}$, viscosity, and osmolarity), as well as vein assessment (full, bouncy, straight).

\subsubsection{Site Location}

When choosing a site for PIVC insertion in the pediatric patient, consideration must be given to the site that is going to least interrupt the child's usual play and activity as they are less likely to be protective of their PIVC as an adult patient might—see Table 15.1. In particular, avoid placing a PIVC in the hand of the thumb that they might suck for comfort and in areas of flexion such as the wrist and antecubital fossa. The preferred cannulation sites are the veins of the non-dominant forearm. These veins are often easy to palpate in older children but might be more difficult in the chubby toddler. The use of technology such as ultrasound, which will be discussed later in this chapter, might be of assistance in this instance.

When upper extremity veins are inaccessible, the dorsal veins of the foot or the saphenous veins of the lower extremity may be used in toddlers that are not yet mobile. Other alternative intravenous cannulation sites that have been used in neonates and young infants include the scalp veins.

Contraindications to an insertion site in the body may include edema, infection, phlebitis, sclerosed veins, previous intravenous infiltration, burns, skin injury such as eczema, or traumatic injury proximal to the insertion site and surgical procedures affecting the extremity.

When traditional PIVC insertion techniques such as palpation fail and multiple attempts at vascular access are unsuccessful, the use of visual aids such as ultrasound and other ultraviolet light might be required. Practitioners have described increased success when PIVCs are inserted into deeper vessels with the aid of longer catheters in adults (Fabrizio Elia et al. 2012), and ultrasound guidance is similarly beneficial in both the adult and pediatric population (Benkhadra et al. 2012; Stolz et al. 2015). The use of technology to assist in PIVC insertion in children with difficult intravenous access (DIVA) will be discussed later in this chapter.

\subsection{Midlines}

\subsubsection{Vein Options}

Midlines can be inserted in both the upper and lower extremities. The ultimate goal of midline insertion is to extend the dwell of the infusion therapy device for medication that can be deliv- 
Table 15.1 PIVC sites: clinical and practical considerations in pediatrics

\begin{tabular}{|c|c|}
\hline Location/characteristics & Clinical considerations \\
\hline $\begin{array}{l}\text { Dorsal metacarpal veins } \\
\text { Between the metacarpal bones on the dorsal side of the hand } \\
\text { Superficial veins, easily visualized } \\
\text { Easy to insert, good option for day infusion or one-off } \\
\text { procedure }\end{array}$ & $\begin{array}{l}\text { For short-term access only } \\
\text { Tip of catheter should not extend over the wrist } \\
\text { joint } \\
\text { Consider the impact that restricting the use of the } \\
\text { hand will present }\end{array}$ \\
\hline $\begin{array}{l}\text { Dorsal venous network } \\
\text { Formed by the union of metacarpal veins, on the dorsal aspect } \\
\text { of the forearm } \\
\text { Most commonly used due to accessibility and visibility }\end{array}$ & $\begin{array}{l}\text { Comfortable site for patient } \\
\text { Not always prominent, difficult to visualize } \\
\text { particularly in chubby infants and toddlers } \\
\text { Avoid placement over the wrist/prominent ulna } \\
\text { bone which can cause mechanical phlebitis or } \\
\text { dislodgement }\end{array}$ \\
\hline $\begin{array}{l}\text { Cephalic vein } \\
\text { Runs the length of the arm from the wrist to the lateral aspect } \\
\text { of the upper arm to the shoulder } \\
\text { Easy to palpate } \\
\text { Does not restrict patient activity as hands are free } \\
\text { Easy to secure and maintain on the forearm } \\
\text { Preferred site for prolonged peripheral intravenous therapy }\end{array}$ & $\begin{array}{l}\text { Radial nerve runs parallel } \\
\text { Avoid insertion in the wrist area due to increased } \\
\text { risk of inadvertent arterial puncture (Lirk et al. } \\
2004 \text { ) } \\
\text { Avoid in patients who might require future fistula } \\
\text { formation }\end{array}$ \\
\hline $\begin{array}{l}\text { Median cubital vein } \\
\text { Crosses the antecubital fossa } \\
\text { Preferred site during urgent/trauma management due to easy } \\
\text { access and capacity to accommodate large-bore PIVC } \\
\text { Commonly used to draw blood }\end{array}$ & $\begin{array}{l}\text { Nerve endings in this area may result in painful } \\
\text { venipuncture } \\
\text { Brachial artery lies medial; therefore caution } \\
\text { should be taken to avoid inadvertent arterial } \\
\text { puncture } \\
\text { Limits patient's mobility due to joint articulation } \\
\text { Prone to failure due to movement, blockage, } \\
\text { dislodgement, infiltration, and infection }\end{array}$ \\
\hline $\begin{array}{l}\text { Accessory cephalic vein } \\
\text { Branches off the cephalic vein } \\
\text { Joins the cephalic again at the antecubital fossa } \\
\text { PIVC insertion at this site does not restrict movement } \\
\text { Easily stabilized }\end{array}$ & Avoid catheter tip placement at joint articulation \\
\hline $\begin{array}{l}\text { Basilic vein } \\
\text { Runs the entire length if the arm from the wrist to axilla } \\
\text { Runs along the medial aspect of the upper forearm } \\
\text { Runs deep above the elbow and combines with the brachia } \\
\text { veins to form the axillary vein } \\
\text { First choice for PICC insertion }\end{array}$ & $\begin{array}{l}\text { Vein rotates around the arm and requires firm skin } \\
\text { tension to stabilize vein } \\
\text { Avoid use for short-term devices if longer-term } \\
\text { device might be required }\end{array}$ \\
\hline $\begin{array}{l}\text { Great and small saphenous vein } \\
\text { Generally visible, palpable, and easily accessible } \\
\text { Best used in patients not yet walking } \\
\text { Straight, easy to secure }\end{array}$ & $\begin{array}{l}\text { Decreases mobility in active toddler } \\
\text { Often deep within tissues and requires ultrasound } \\
\text { insertion }\end{array}$ \\
\hline $\begin{array}{l}\text { Dorsal venous arch } \\
\text { Superficial vessel on dorsum of foot } \\
\text { Best used in patients not yet walking } \\
\text { Avoid tip crossing ankle joint }\end{array}$ & Decreases mobility in active toddler \\
\hline
\end{tabular}

ered into the peripheral venous system. Ideally, a midline will be inserted into a vein in the upper arm or upper thigh region, so the tip, while still situated in a peripheral vein, is ideally situated in a large peripheral vein to increase natural hemodilution of intravenous medication. As veins move proximally toward the heart, they increase in size.

\subsubsection{Site Location}

The optimal insertion site is the non-dominant arm within the middle third of the upper arm. For the pediatric patient population, the fixed length of midlines currently available requires the insertion site to be tailored to the length of 
the catheter. For example, if an $8 \mathrm{~cm}$ midline is all that is available, the insertion site should start $8 \mathrm{~cm}$ below the axillary vein which is ideally where the tip will be positioned. Alternatively, a lower limb insertion should commence at a distance equal to the length of the midline, just distal to the femoral vein for ideal midline tip placement.

Catheters placed within the lower limb have an increased risk of complications such as infection due to close proximity to the nappy area in infants and toddlers and thrombosis (Greene et al. 2015). Placement of midlines in the lower limbs should only be considered as a last resort.

The use of ultrasound to support midline placement has clear benefits as the vein chosen can be assessed for patency along its entire length. Ultrasound also provides additional venous access options that would previously be too deep to palpate using blind punctures and enables site placement proximal to the antecubital fossa which has the advantage of siting the catheter outside the elbow joint.

\subsubsection{Central Venous Access Devices (CVADs)}

The remainder of this chapter will review the catheter, site, vein, and technology choice for insertion of various central venous access devices or central venous catheters to ensure vessel health and preservation throughout the child's lifespan and through to adulthood. A central venous access device (CVAD) is defined as a catheter placed with the tip positioned within the region of the cavoatrial junction (Silberzweig et al. 2003). When placing a CVAD with its insertion in the neck, the cavoatrial junction is defined as two vertebral body units below the carina. This is a reliable marker in the adult and adolescent patient; however, variability might be found in younger pediatric patients and should be used with caution as an absolute marker (Baskin et al. 2008; Song et al. 2015).

Patient assessment prior to choice of vein, site, and device should include information of previous indwelling CVADs and reason for use and removal that might limit available sites for future access. Likewise, it is also recommended that documentation at the conclusion of CVAD insertion should include relevant demographic and procedural CVAD information including patient consent, selection and exclusion criteria for device and site choice, reason for device insertion, and intended length of use (Silberzweig et al. 2003).

\subsection{PICCs}

\subsubsection{Vein Options}

PICCs are inserted into peripheral veins of the upper arm (basilic, brachial, or cephalic) with the tip of the catheter advanced to the cavoatrial junction. If placement of PICC in the upper limb is not possible, lower limb PICC insertion is necessary. The vein of choice is usually the greater saphenous found on the medial aspect of the lower limb, and the tip of the catheter is then advanced to the inferior vena cava, located above the level of the diaphragm (Gorski et al. 2016) (Chap. 14). Cannulation of the lower limb veins for PICC insertion is associated with a higher incidence of thrombosis; however, as with midlines, this risk is lower in children and infants than in adults. Therefore this is an acceptable alternative when cannulation of the upper extremities has failed in a child or infant (Spentzouris et al. 2012).

\subsubsection{Site Location}

The ideal site for insertion of PICC in the upper limb is in the middle third of the upper arm (Dawson 2011; Simcock 2008). In some pediatric patients, finding a suitable vein in this location can be challenging. This might be due to venous thrombosis or stenosis resulting from multiple previous PICC insertions; anatomical limitation including nerves and artery located anterior to the intended vein; or, in the very small neonate, vein size is simply not 
large enough to accommodate an appropriate sized PICC for the treatment required. In this situation, veins closer to the axilla may be more appropriate to access; however, placing a PICC insertion site at the axilla makes care and maintenance challenging. To avoid this suboptimal exit site, tunneling the PICC distal to the insertion site has proven successful (Ostroff and Moureau 2017). In this way, the PICC insertion/exit site is appropriately placed in the middle third of the upper arm, and the vessel accessed in the axillar region is sufficient for the intended treatment.

When PICC placement via an upper limb vessel is not possible in neonates and pediatric patients, it is acceptable to place a PICC via a lower limb vessel such as the greater saphenous, popliteal, or common femoral vein. The obvious limitation to placing a PICC/smallbore catheter in the lower limb is mobility and soiling in the diaper area which should be considered when choosing a site. If, after thorough venous assessment, the common femoral vein is the most appropriate vein for PICC insertion, tunneling the PICC away from the insertion site will remove the insertion/exit site from the threat of contamination from the nappy and may increase the ease of site visibility and care and maintenance-see Fig. 15.2.

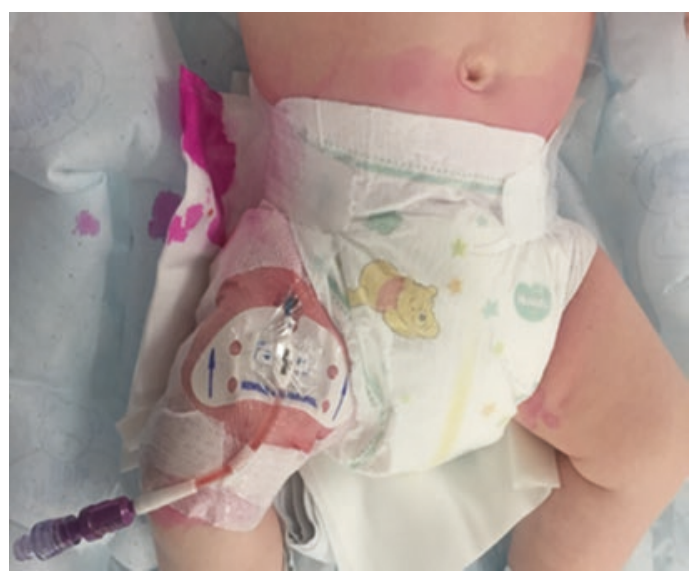

Fig. 15.2 Tunneled femoral CVAD (used with permission T. Kleidon)

\subsection{Non-Tunneled CVCs}

\subsubsection{Vein Options}

Short, non-tunneled CVCs are usually inserted into the neck (internal jugular, external jugular, subclavian, and brachiocephalic) or groin (great saphenous and common femoral).

\subsubsection{Site Location}

Securing a CVC in pediatric patients can prove challenging due to anatomical limitations of small neck size and the potential for contamination from the nappy if the CVC is placed in the groin. Cannulation of the internal jugular has predominantly been achieved by utilizing the shortaxis view (i.e., ultrasound probe is placed in cross section to the internal jugular vein, and the needle puncture is in-line with jugular but out of plane with the probe). While the advantage to this approach is increased cannulation success, postinsertion can be problematic when trying to secure a dressing and maintain CVC function in the pediatric population (Gorski et al. 2016). An alternative approach is to place the ultrasound probe in the supraclavicular notch (out of plane to the vein) and utilizing an out-of-plane approach to the vein, approach the internal jugular from the lateral edge of the probe (in line with the ultrasound probe), and achieve access from a low jugular approach which improves the nurses' ability to secure the catheter to the anterior chest wall (Fig. 15.3).

A similar approach is used to puncture the subclavian vein. Using a long-axis view, the ultrasound probe is often placed in an infraclavicular position, and the needle is placed as close as possible to the lateral edge of the probe and enters the axillar vein or subclavian under direct visualization.

\subsection{Approach to Insertion}

Patient position can impact the likelihood of a successful central venous access procedure. Place the patient in the Trendelenburg position 

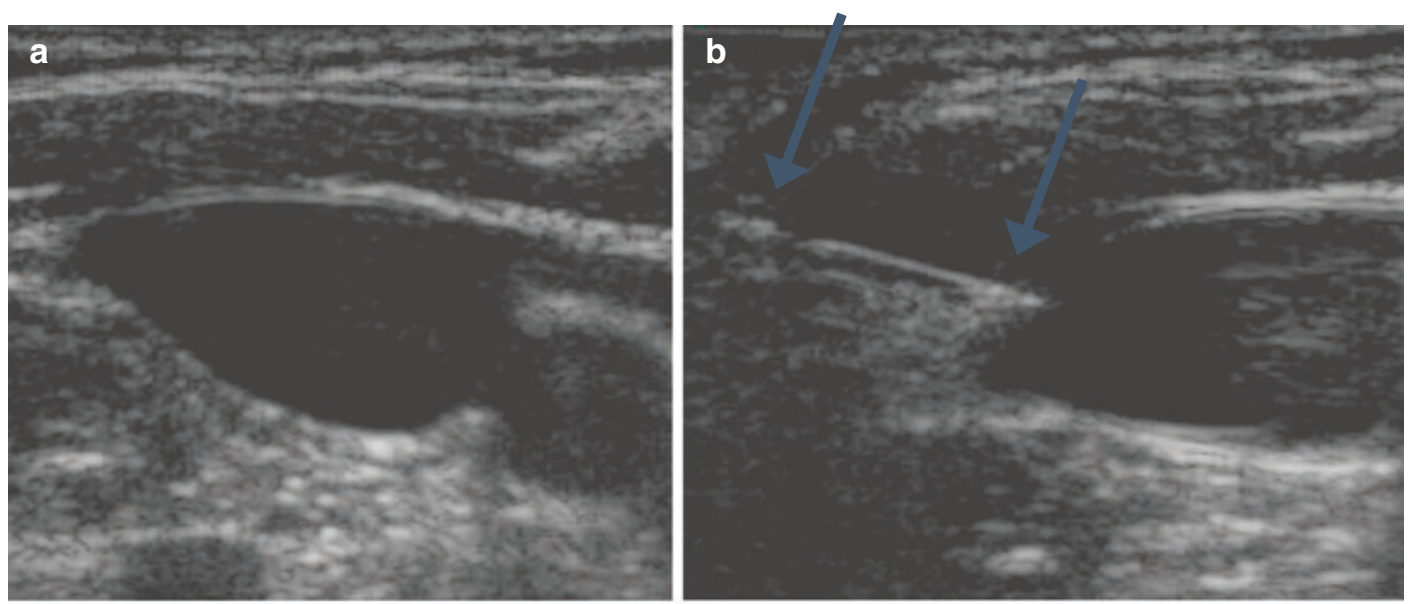

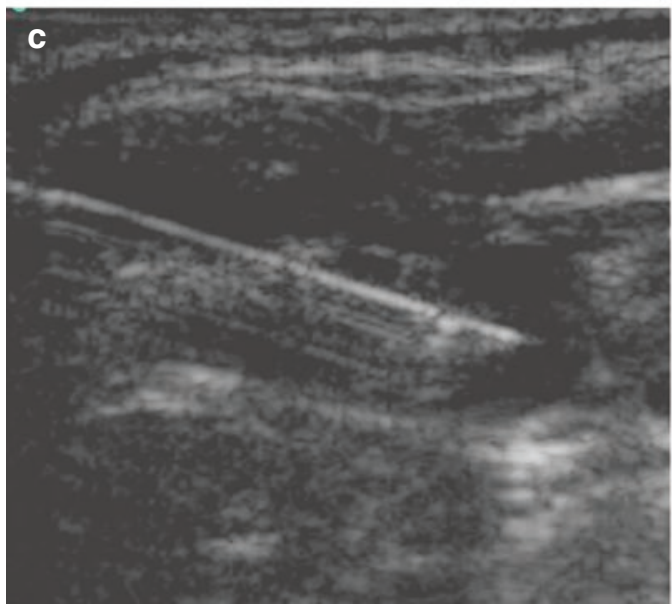

Fig. 15.3 (a-d) Ultrasound image showing RIJV lying lateral to common carotid artery; (b) needle indenting wall of the vein (c) successful cannulation of the IJV

or have a small roll placed under their shoulders (unless contraindicated due unstable c-spine that may occur due to injury or disease) for central vein cannulation of veins in the neck region. Trendelenburg position allows gravity to enhance central venous filling to create a larger target for venipuncture and minimize risk of air embolus (Bannon et al. 2011). A roll under the hip will elevate the common femoral vein and aid cannulation; however initiating the reverse Trendelenburg position will not substantially increase femoral vein size.

External landmarks, venography, and ultrasound are used to localize central vessels including internal and external jugular, subclavian,

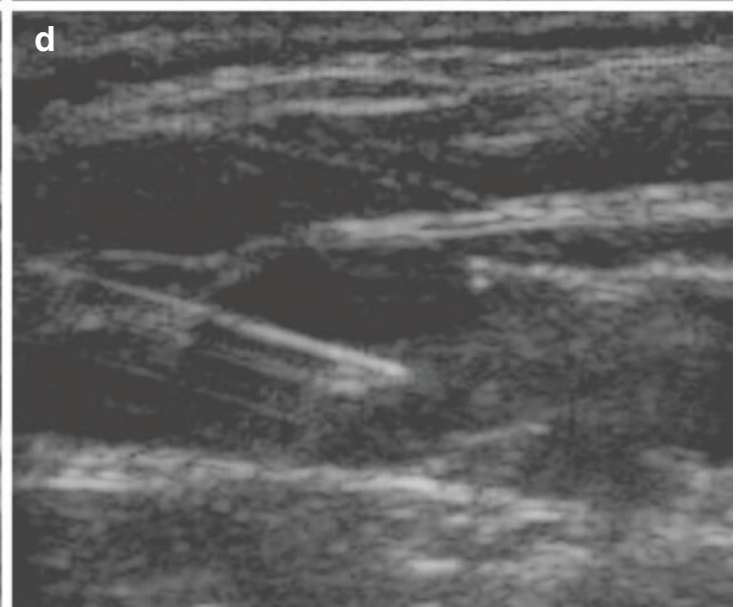

shown by needle moving freely within the vessel (d) aspiration of blood confirming successful cannulation (used with permission T. Kleidon)

axillary, common femoral, and brachiocephalic (innominate) veins. The ultrasound-guided approach to cannulation of the internal jugular vein has been shown to have a lower complication rate, time to insertion, and increased first time success compared to landmark-guided puncture (Lau and Chamberlain 2016).

The Society of Interventional Radiology reporting standards for central venous access insertion (Silberzweig et al. 2003) recommends reporting the method and route of venous access, including patient position, technique for vein localization, and venous puncture site selection. Furthermore, also report the number of catheterization attempts, defined as the 
passing of a needle through the skin with the intent to obtain venous access, and any inadvertent arterial punctures. Venous anomalies such as stenosis and occlusion should also be reported.

\subsection{Tunneled and Totally Implanted Devices}

\subsubsection{Vein Options}

The right internal jugular vein is considered the access site of choice for central venous cannulation. Advantages include a superficial location, easy visualization with ultrasound, and a straight trajectory to the superior vena cava. Additionally, cannulation of the internal jugular rather than subclavian vein avoids "pinch-off syndrome" and avoids potential stenosis of the subclavian vein (Bannon et al. 2011). This is an important vessel health and preservation consideration in pediatric patients with chronic renal disease, as they may require formation of an arteriovenous fistula in the future, as a means of providing hemodialysis.

Cannulation of the innominate vein or brachiocephalic vein is an innovative approach to central venous access. Place the ultrasound probe in the supraclavicular notch, and angle the probe caudally to obtain a longitudinal view of the junction of the internal jugular vein, subclavian vein, and brachiocephalic vein. This is a useful puncture site when the internal jugular veins are small or absent bilaterally or if previous attempts to puncture the jugular vein have failed.

\subsubsection{Site Location}

The tunneled catheter exit site or implanted port pocket is usually placed over the upper anterior chest or the inner aspect of the upper extremity (Barnacle et al. 2008). Reports have described alternative access routes for tunneled central venous catheter including transfemoral, translumbar, and transhepatic (Roebuck et al. 2005b). Circumstances where this route might be required are in extreme cases of venous insufficiency whereby all traditional sites have been used and are no longer available (Barnacle et al. 2008).

\subsection{Technology Emergence}

Ultrasound technology has been found to be invaluable in vascular access procedures, particularly for deep veins (Lamperti and Pittiruti 2013; Simon and Saad 2012). However, there is now a range of near-infrared devices available that are useful for peripheral cannulation of the more superficial veins (Lamperti et al. 2014; Moureau et al. 2013). This technology is still fairly new, and although there have been some evaluations, to properly understand the potential benefits of this technology, further evaluations are necessary (Phipps et al. 2012).

\subsubsection{Near-Infrared (nIR)}

Near-infrared is light technology that aids in achieving vascular access of superficial peripheral veins in neonates, patients with complex medical conditions and the severely dehydrated patient (Gorski et al. 2016). nIR technology captures an image of the veins and reflects it back to the skin's surface. nIR can be used as a real-time cannulation technique or as an aid to identify viability of peripheral venous sites as well as offering more information about vein selection (i.e., bifurcation, tortuous vessels, and viable palpable vein - v- thrombosed vein).

\subsubsection{Ultrasound}

Ultrasound evaluation of veins is an invaluable resource to assess venous course, identify underlying structures such as arteries and nerves and ensure venous patency before venous puncture (Fig. 15.4). Real-time ultrasound guidance has 
been shown to reduce complications, procedure time, and improve first time puncture and overall technical success of both peripheral and central venous catheter placement (Benkhadra et al. 2012; Lau and Chamberlain 2016).

Additionally, the use of ultrasound for PIVC insertion in pediatrics facilitates the operator to choose a catheter length that will ensure sufficient catheter is residing within the vein lumen. The ultrasound screen indicates vessel depth

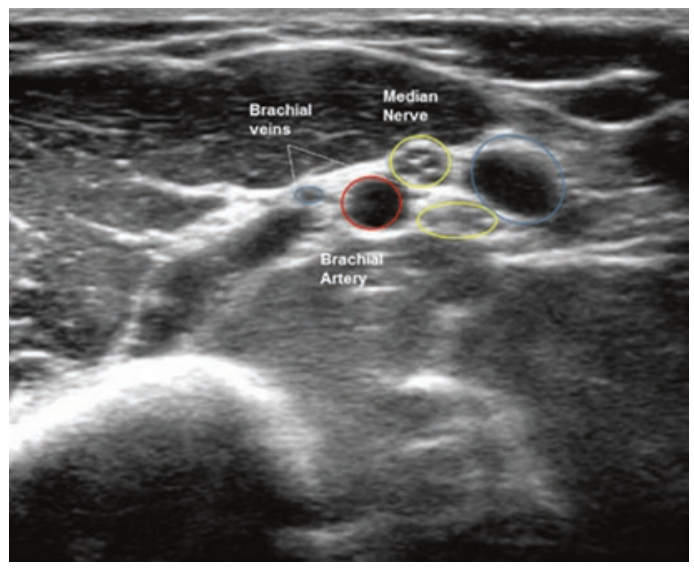

Fig. 15.4 Identification of vein in relation to underlying structures (used with permission T. Kleidon)
(Fig. 15.5); therefore a vessel that is $1 \mathrm{~cm}$ deep should have a catheter that is equal to or greater than $2 \mathrm{~cm}$ long to ensure half of the catheter is anchored within the vessel.

The use of technology to identify CVAD tip position intraoperatively has the advantage of increased accuracy, reduced delays to start of treatment, and reduced complications such as dislodgement and risk of contamination if catheter repositioning is required.

\subsubsection{Fluoroscopy}

Ideally the catheter tip of a CVAD that is placed in the upper body is advanced to the cavoatrial junction. For lower body insertions, the catheter tip should be positioned in the inferior vena cava, above the level of the diaphragm (Gorski et al. 2016). This ensures a tip position with high blood flow which prevents thrombosis and is also positioned external to the atrium to prevent arrhythmias and pericardial erosion and cardiac tamponade. The radiographic surface landmarks that correspond to this position are less clear in the pediatric patient than the adult patient. The carina and inferior border of the right main bron-
Fig. 15.5 Ultrasound image indicating vessel depth. This information should be used to choose appropriate length PIVC (used with permission T. Kleidon)

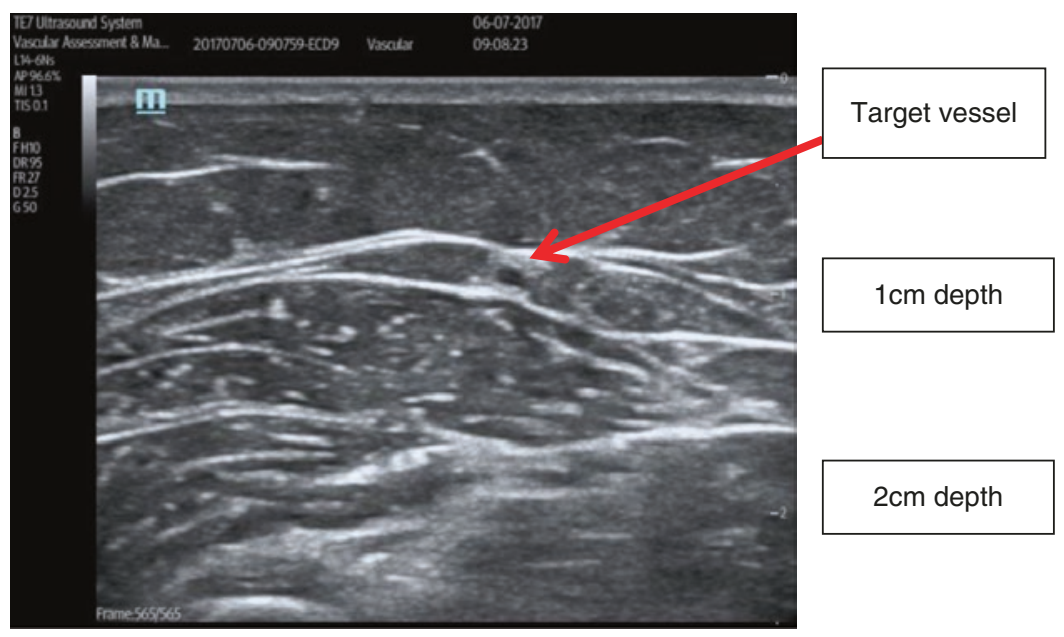


chus are appropriate landmarks in pediatrics to ensure safe positioning of the catheter tip (Gorski et al. 2016).

\subsubsection{Electrocardiogram (ECG)}

Electrocardiogram is a recent accurate and safe alternative to the use of fluoroscopic-guided tip position for insertion of CVAD. Although this technology has not been evaluated as widely in pediatrics as it has in the adult population, small, multicenter studies have demonstrated safety and accuracy in the pediatric population (Rossetti et al. 2015). This technology allows the inserter to identify accurate tip placement within the cavoatrial junction with corresponding changes in ECG trace. Caution should be employed when using this technology for patients with known history of cardiac dysrhythmias and an absence or alteration in the P-wave (Chap. 7).

\subsection{Conclusion}

The percutaneous technique to cannulate central veins reduced the need for open, surgical cut-down procedures and the associated morbidity that can result from the large incision wound and vein trauma (Roebuck et al. 2005a, b). Traditionally, the use of the percutaneous technique to successfully cannulate a central vessel was reliant on the relationship between surface anatomic landmarks and the anatomic structures beneath the skin. Contemporary approaches to percutaneous cannulation of central vessels have involved the use of real-time ultrasound visualization which enhances the safety of puncturing the internal jugular, brachiocephalic, and femoral veins. Ultrasound also offers the axillary vein as a "visible" alternative to blind subclavian approach which is difficult to visualize with ultrasound due to overlying bony structures (Sharma et al. 2004). In today's modern healthcare, pediatric patients are living longer and many into adulthood. This means they have increasingly complex comorbidities that will often require long term and possibly lifelong intravenous treatment. The ultimate goal of the vascular access healthcare professional should be to ensure long-term viability of vessels through careful assessment, planning, insertion, and management.

\section{Case Study}

Geoffrey is a 2-year-old boy who requires a 5-day course of intravenous antibiotics to treat cellulitis of the right thumb. Geoffrey still sucks his left thumb. Consider the potential sites available for PIVC insertion in this instance. What considerations should be made when planning for device insertion?

Abbie is a 12-year-old girl with rheumatoid arthritis. Abbie attends the outpatient department for monthly infusions of rituximab. What different considerations can you see in the two scenarios?

\section{Case Study}

Claire is a 3-year-old recently admitted with disseminated infected eczema. Most of Claire's face and upper and lower limbs are affected, especially over areas of flexion. In addition to administration of intravenous flucloxacillin, Claire has wet wraps to her limbs as part of her treatment plan.

As Claire's vascular access nurse, what are the clinical considerations when choosing a vascular access device for her treatment? How can you reduce the risk of vascular access device failure and ensure its longevity for the entire treatment? 


\section{Case Study}

Billy is a 12-year-old with cystic fibrosis who requires insertion of PICC for 14-28 days of intravenous antibiotics. Billy has recently commenced high school and has become non-compliant with his medication and physiotherapy, and this is his third admission for chest optimization this year.

Ultrasound assessment of Billy's upper limbs reveals a large basilic vein in the region of the antecubital fossa that narrows significantly as it advances proximally and becomes large again at the axilla. It is difficult to visualize beyond the axilla due to normal anatomical placement of bony structures such as the clavicle; however, there is no evidence of superficial, collateral vessels on the chest wall.

What are your considerations when placing a PICC for Billy?

\section{Case Study}

Xavier is a 2-week-old baby transferred to your hospital with a history of thrombocytopenia, neutropenia, and uncorrected coagulopathy. Xavier currently has no peripheral or central venous access as multiple attempts by the intensivist to insert a PIVC have failed. You have been asked to insert a vascular access catheter that will provide reliable, medium to long-term access for blood, and blood product transfusion and sampling.

1. What are your immediate considerations and potential risk factors?

2. What are the potential vascular access options suitable for this patient?

\section{Case Study}

Audrey is a 14-year-old who has recently been diagnosed with acute myeloid lymphoma. Prior to diagnosis, Audrey led an active teenage lifestyle and is a member of her college water polo team. Audrey will require intensive chemotherapy, infusion of blood and blood products, multiple blood tests, and eventual bone marrow transplant. As Audrey's infusion nurse specialist, you are discussing the various CVAD options with Audrey and her family.

1. What CVAD options do you consider appropriate for this treatment?

2. What are some of the advantages and disadvantages of the various devices you will discuss with Audrey and her family?

3. What are the practical considerations of inserting a CVAD in a prepubescent/ pubescent female?

\section{Case Study}

You are a nurse in a medical day unit. The majority of your patients attend the unit on a regular basis ranging from weekly, monthly, to quarterly appointments for infusion of medication for prevention and treatment of various disease processes. Some of these patients are becoming increasingly difficult to place a PIVC due to multiple PIVC insertions and side effects of their treatment increasing their adiposity.

You don't currently have a vascular access team in your hospital, and medical officers rotate through this unit on a 3-6 monthly basis.

1. What processes can you implement to reduce the pain and discomfort of multiple PIVC insertion attempts?

2. What technology factors might be useful in this setting?

3. What patient factors might improve PIVC insertion? 


\section{Summary of Key Points}

1. Prior to selecting the insertion site, clinicians should consider the patient's condition, developmental age, skin condition, previous vascular access history, duration of infusion therapy, and patient preference where possible.

2. Determining site placement requires different considerations with pediatrics versus adults. Some considerations include:
(a) Mobility
(b) Skin integrity
(c) Thumb sucking
(d) Diaper use
(e) Activities (older children)

3. The introduction of technologies such as nIR, ultrasound, fluoroscopy, and EKG has increased the success rates of VAD insertions with pediatric patients and should be used as a mean of vessel health and preservation, reducing the number of sticks required for successful access.

4. The ultimate goal of the vascular access healthcare professional working with pediatric patients should be to ensure long-term viability of vessels through careful assessment, planning, insertion, and management.

\section{References}

Bannon MP, Heller SF, Rivera M. Anatomic considerations for central venous cannulation. Risk Manage Healthcare Policy. 2011;4:27.

Barnacle A, Arthurs OJ, Roebuck D, Hiorns MP. Malfunctioning central venous catheters in children: a diagnostic approach. Pediatr Radiol. 2008;38(4):363-78. https://doi.org/10.1007/s00247007-0610-2. quiz 486-367.

Baskin KM, Jimenez RM, Cahill AM, Jawad AF, Towbin RB. Cavoatrial junction and central venous anatomy: implications for central venous access tip position. J Vasc Interv Radiol. 2008;19(3):359-65. https://doi. org/10.1016/j.jvir.2007.09.005.

Benkhadra M, Collignon M, Fournel I, Oeuvrard C, Rollin $\mathrm{P}$, Perrin M, et al. Ultrasound guidance allows faster peripheral IV cannulation in children under 3 years of age with difficult venous access: a prospective randomized study. Paediatr Anaesth. 2012;22(5):449-54. https://doi.org/10.1111/j.1460-9592.2012.03830.x.

Dawson RB. PICC zone insertion method ${ }^{\mathrm{TM}}\left(\mathrm{ZIM}^{\mathrm{TM}}\right)$ : a systematic approach to determine the ideal insertion site for PICCs in the upper arm. J Assoc Vasc Access. 2011;16(3):162-5. https://doi.org/10.2309/ java.16-3-5.

Elia F, Ferrari G, Molino P, Converso M, De Filippi G, Milan A, Aprà F. Standard-length catheters vs long catheters in ultrasound-guided peripheral vein cannulation. Am J Emerg Med. 2012;30(5):712-6. https:// doi.org/10.1016/j.ajem.2011.04.019.

Gorski L, Hadaway L, Hagle M, McGoldrick M, Orr M, Doellman D. Infusion therapy: standards of practice. J Infus Nurs. 2016;39(1S):S1-S159.

Greene MT, Flanders SA, Woller SC, Bernstein SJ, Chopra V. The association between PICC use and venous thromboembolism in upper and lower extremities. Am J Med. 2015;128(9):986-93.e1. https://doi. org/10.1016/j.amjmed.2015.03.028.

Lamperti M, Pittiruti M. II. Difficult peripheral veins: turn on the lights. Br J Anaesth. 2013;110(6):888-91. https://doi.org/10.1093/bja/aet078.

Lamperti M, Moureau N, Kelly LJ, Dawson R, Elbarbary M, van Boxtel AJ, Pittiruti M. Competence in paediatric central venous lines placement. Br J Anaesth. 2014;112(2):383. https://doi.org/10.1093/bja/aet557.

Lau C, Chamberlain R. Ultrasound-guided central venous catheter placement increases success rates in pediatric patients: a meta-analysis. Pediatr Res. 2016;80(2):17884. https://doi.org/10.1038/pr.2016.74.

Lirk P, Keller C, Colvin J, Colvin H, Rieder J, Maurer $\mathrm{H}$, Moriggl B. Unintentional arterial puncture during cephalic vein cannulation: case report and anatomical study. Br J Anaesth. 2004;92(5):740-2. https://doi. org/10.1093/bja/aeh118.

Moureau N, Lamperti M, Kelly L, Dawson R, Elbarbary M, van Boxtel J, Pittiruti M. Evidence-based consensus on the insertion of central venous access devices: definition of minimal requirements for training. $\mathrm{Br} \mathrm{J}$ Anaesth. 2013;110(3):333-46.

Ostroff M, Moureau N. Report of modification for peripherally inserted central catheter placement: subcutaneous needle tunnel for high upper arm placement. J Infus Nurs. 2017;40(4):232-7. https://doi. org/10.1097/nan.0000000000000228.

Phipps K, Modic A, O'Riordan MA, Walsh M. A randomized trial of the vein viewer versus standard technique for placement of peripherally inserted central catheters (PICCs) in neonates. J Perinatol. 2012;32(7):498-501. https://doi.org/10.1038/jp.2011.129.

Roebuck D, Kleidon T, McLaren CA, Barnacle A. Internal jugular vein (IJV) patency after central venous (CV) access [abstract]. Pediatr Radiol. 2005a;35(suppl 1):s76.

Roebuck D, Kleidon T, Mclaren C, Barnacle A. Central venous access by recanalization of occluded central veins [abstract]. Pediatr Radiol. 2005b;35(Suppl 1):S76. 
Rossetti F, Pittiruti M, Lamperti M, Graziano U, Celentano D, Capozzoli G. The intracavitary ECG method for positioning the tip of central venous access devices in pediatric patients: results of an Italian multicenter study. J Vasc Access. 2015;16(2):137-43. https://doi. org/10.5301/jva.5000281.

Sharma A, Bodenham AR, Mallick A. Ultrasound-guided infraclavicular axillary vein cannulation for central venous access. Br J Anaesth. 2004;93(2):188-92. https://doi.org/10.1093/bja/aeh187.

Silberzweig JE, Sacks D, Khorsandi AS, Bakal CW. Reporting standards for central venous access. J Vasc Interv Radiol. 2003;14(9 Pt 2):S443-52.

Simcock L. No going back: advantages of ultrasoundguided upper arm PICC placement. J Assoc Vasc Access. 2008;13(4):191-7. https://doi.org/10.2309/ java.13-4-6.

Simon PO Jr, Saad WE. Ultrasound-guided vascular access. Ultrasound Clin. 2012;7:283-97. https://doi. org/10.1016/j.cult.2012.04.001.
Song YG, Byun JH, Hwang SY, Kim CW, Shim SG. Use of vertebral body units to locate the cavoatrial junction for optimum central venous catheter tip positioning. Br J Anaesth. 2015;115(2):252-7. https://doi. org/10.1093/bja/aev218.

Spentzouris G, Scriven RJ, Lee TK, Labropoulos N. Pediatric venous thromboembolism in relation to adults. J Vasc Surg. 2012;55(6):1785-93. https://doi. org/10.1016/j.jvs.2011.07.047.

Stolz LA, Stolz U, Howe C, Farrell IJ, Adhikari S. Ultrasound-guided peripheral venous access: a meta-analysis and systematic review. J Vasc Access. 2015;16(4):321-6. https://doi.org/10.5301/ jva.5000346.

Open Access This chapter is licensed under the terms of the Creative Commons Attribution 4.0 International License (http://creativecommons.org/licenses/by/4.0/), which permits use, sharing, adaptation, distribution and reproduction in any medium or format, as long as you give appropriate credit to the original author(s) and the source, provide a link to the Creative Commons license and indicate if changes were made.

The images or other third party material in this chapter are included in the chapter's Creative Commons license, unless indicated otherwise in a credit line to the material. If material is not included in the chapter's Creative Commons license and your intended use is not permitted by statutory regulation or exceeds the permitted use, you will need to obtain permission directly from the copyright holder. 